\title{
Yung YAU
}

\section{Nepomembno ali prezrto? Protisocialno vedenje $\mathbf{v}$ zasebnih stanovanjih $\mathbf{v}$ Hongkongu}

Zaradi vse večjih nevšečnosti, ki jih na stanovanjskem področju povzročajo protisocialno vedenje (ang. antisocial behaviour, v nadaljevanju: ASB) in problemi v soseski, mnoge zahodnjaške vlade $\mathrm{v}$ svojih programih stanovanjske politike namenjajo nadzorovanju ASB osrednje mesto. Vendar je za spopadanje z ASB pogosto potrebno veliko političnih ukrepov. Čeprav se ASB in njegovemu nadzoru namenja veliko znanstvene pozornosti, je bil do zdaj glavni poudarek skoraj vedno predvsem na socialnih stanovanjih, pri čemer ni jasno, ali ta problem pri drugih vrstah stanovanj ne obstaja ali je tam preprosto prezrt. Članek temelji na raziskavi zasebnih stanovanjskih naselij v Hongkongu ter v njem sta preučena obseg in resnost problema ASB v zasebnih stanovanjih. Kaže, da ta problem pri stanovalcih povzroča veliko skrbi ter da se mnogi stanovalci pritožujejo nad hrupom in odlaganjem smeti v svojem bivalnem okolju. Po drugi strani ima večina stanovalcev občutek, da upravniki večstanovanjskih stavb pri reševanju teh problemov niso uspešni in da se z njimi ne spopadajo na primeren način. Upravniki se pri odzivanju na ASB spopadajo s številnimi neizogibnimi težavami, ki so posledica tega, da jih izberejo vsi lastniki stanovanj skupaj in da nimajo pooblastil za ukrepanje. Nadzorovanje nekaterih nevšečnosti v soseščinah je namreč zelo zahtevno in drago. Članek se konča s predlogom za empirično raziskavo, ki bi razložila širjenje ASB $\mathrm{z}$ vidika transakcijskih stroškov.

Ključne besede: protisocialno vedenje, nevšečnosti v soseščinah, zasebna stanovanja, mnenja stanovalcev, Hongkong 


\section{Uvod}

Vsem stanovalcem je zelo pomembno, da imajo na voljo kakovostno življenjsko okolje. Kakovost stanovanj pa ni odvisna le od njihove oblike in kakovosti gradnje, saj k dobremu počutju stanovalcev močno prispeva tudi uspešnost dela upravnikov večstanovanjskih stavb (Yau, 2010). Poleg tega, da stanovalci ne sodelujejo pri skrbi za stavbo in da za upravljanje večstanovanjskih stavb običajno nobeden ne prevzema odgovornosti, ni sprejemljivo niti vedenje prebivalcev, še ena pogosta težava, ki slabša bivalne razmere $\mathrm{v}$ stanovanjskih soseskah. Za nesprejemljivo vedenje stanovalcev se v Avstraliji in Veliki Britaniji pogosto uporablja izraz protisocialno vedenje (ang. antisocial behaviour, v nadaljevanju: ASB), drugje pa se uporabljajo tudi izrazi nevljudnost, socialna motnja, sosedske nevšečnosti in kazniva dejanja zoper kakovost življenja (ang. quality-of-life crimes). Pogoste oblike vključujejo hrup, odlaganje smeti, grafite, neustrezno uporabo skupnih prostorov, neodgovorno ravnanje z lastnimi hišnimi ljubljenčki in druge primere vandalizma. Kako velik je dejansko ta problem, potrjuje naraščajoče število pritožb in rastoče nezadovoljstvo stanovalcev z njihovimi stanovanjskimi soseskami (na primer urad škotske vlade za socialne raziskave, 2007; inšpektorat za kazensko pravosodje na Severnem Irskem, 2008). ASB ima lahko različne posledice: od zmanjšanega zadovoljstva s stanovanjem ter negativnih vplivov na fizično in psihično zdravje do ogrožanja družbene trdnosti (Pacione, 1982; Curtis idr., 2004; Agyemang idr., 2007; Jacobson idr., 2008).

V zadnjem desetletju so oblikovalci politike, stanovanjski organi, stanovalci in strokovnjaki v zahodnjaških državah problemu ASB začeli posvečati več pozornosti. Za odpravljanje te težave je bilo v okviru različnih pristojnosti uvedeno več ukrepov, kot so sodne prepovedi, odredbe o ASB, posebni zakoni za starše, pogodbe o sprejemljivem vedenju, najemi za poskusno obdobje, nadzorniki soseske in programi družinskega posredovanja. Čeprav so ti ukrepi različno učinkoviti, je jasno, da se nadzor nad ASB izvaja pristransko glede na vrsto stanovalcev, čeprav so problemi v zvezi z ASB in sosedski spori v tem pogledu nevtralni (Scott in Parkey, 1998; Flint in Nixon, 2006). Pogosto se namreč preverja le najemnike socialnih stanovanj, ne pa tudi stanovalcev drugih vrst stanovanj. Raziskava, ki sta jo opravila Carr in Cowan (2006), kaže, da je ugotavljanje, ali so socialna stanovanja nevarna in ali povzročajo ASB, pravzaprav samoizpolnjujoča se prerokba. Avtor tega članka (Yau, 2011a) ugotavlja, da se ASB pojavlja tudi pri drugih oblikah stanovanjskega lastništva. Zato je napačno sklepati, da je ASB samo problem socialnih stanovanj, saj nimamo konkretnih dokazov, ki bi potrjevali, da se ASB pri nesocialnih stanovanjih ne pojavlja.

V Hongkongu se pred letom 2003 ASB ni posvečalo veliko pozornosti. Po izbruhu sindroma akutnega oteženega diha- nja (SARS) v začetku leta 2003 pa je hongkonška vlada odločila, da lahko določene oblike ASB ali nesprejemljivo vedenje stanovalcev vodijo v nehigienske razmere, ki se spreminjajo $\mathrm{v}$ žarišča epidemij. Zato je vlada sprejela več pobud in med drugim poostrila ukrepe proti vedenju, ki ogroža javno zdravje, kot je pljuvanje in namerno odlaganje smeti na javnih mestih (Team Clean, 2003). Poleg tega je bil avgusta 2003 sprejet sistem označevanja za izvajanje najemnišstva $\mathrm{v}$ javnih stanovanjih (ang. Marking Scheme for Tenancy Enforcement in Public Housing Estates) za izboljšanje higienskih in bivalnih razmer v javnih stanovanjih na tem območju. Gre za neke vrste nadzorovanje ASB na stanovanjskem področju. Vendar je tako nadzorovanje diskriminatorno, saj so v sistem označevanja vključeni le najemniki javnih stanovanj, druge oblike stanovanjskega lastništva pa so iz njega izvzete. Pravzaprav se skoraj vsa literatura o ASB v stanovanjskem sektorju osredotoča na javna ali socialna stanovanja. Ni jasno, ali se težava pri drugih oblikah stanovanjskega lastništva ne pojavlja ali pa je preprosto prezrta. Zato članek na podlagi empirične raziskave o zasebnih stanovanjskih naseljih v Hongkongu obravnava obseg in resnost problemov ASB v zasebnih stanovanjih.

$\mathrm{V}$ drugem poglavju je podan splošni pregled problemov, povezanih z ASB. V tretjem poglavju so opisani zgradba in rezultati anketnega vprašalnika, izvedenega v Hongkongu. $V$ četrtem poglavju je predstavljena analiza dejavnikov, ki določajo, kako stanovalci sprejemajo ASB v svojem bivalnem okolju. Težave pri obvladovanju ASB v zasebnih stanovanjih so obravnavane v petem poglavju. Šesto poglavje pa končuje članek in podaja predloge za nadaljnje raziskave.

\section{Pregled težav z ASB po svetu}

Naraščajoče zanimanje za težave $\mathrm{v}$ stanovanjski soseski ali težave, povezane z ASB v stanovanjskem sektorju, lahko pripišemo velikemu številu pritožb v zvezi z različnimi vrstami ASB. V Avstraliji se je na primer $25 \%$ prebivalcev pritožilo zaradi vandalizma, kot so grafiti in materialna škoda v njihovih soseskah (avstralski statistični urad, 2006). Na Severnem Irskem je bilo med letoma 2006 in 2007 prijavljenih 101.561 primerov ASB (inšpektorat za kazensko pravosodje na Severnem Irskem, 2008). Leta 2009 so v ameriški stanovanjski raziskavi (ang. American Housing Survey) v 25,4 milijona stanovanjskih enotah poročali o običajnih težavah v zvezi s hrupom, v 9,8 milijona pa o problemih $\mathrm{v}$ zvezi z odlaganjem odpadkov (ameriški popisni urad, 2010).

Kljub razširjenosti problemov ASB pa še vedno ni splošne definicije tega pojma (Millie, 2009). Definicije se razlikujejo od ustanove do ustanove in glede na okoliščine. Na primer britanski kraljevi inštitut za stanovanjski sektor (1995) je ASB opredelil kot dejanja, ki nasprotujejo družbenim normam in 
sprejetim standardom vedenja. Enota lokalne vlade za informiranje (1997: 5) pa je ASB opredelila kot »vedenje, s katerim se nadleguje skupnost; ki privede do protisocialnega kriminalnega obnašanja ali je drugače protisocialno; ki druge moti pri uživanju v mirni in tihi soseski; ki ustrahuje skupnost ali njen del $\ll$.

V irskem zakonu o stanovanjskem najemu (ang. Residential Tennancies Act) iz leta 2004 pa je bil ASB podrobno opredeljen kot vedenje,

s katerim je izveden prekršek, pri čemer izvršitev tega prekrška precej verjetno neposredno vpliva na dobro počutje ali blagor drugih /.../; ki je vzrok ali bi lahko bilo vzrok za strah, nevarnost, poškodbo, okvaro ali škodo pri kateri koli osebi, ki živi, dela ali je drugače zakonito v zadevnem bivališču ali njegovi bližini, in vključuje nasilje, ustrahovanje, prisilo, nadlegovanje, oviranje ali groženje kateri koli taki osebi /.../, neprestano /.../ preprečuje ali moti mirno bivanje katerim koli drugim osebam v zadevnem bivališču tistega domovanja in ga izvaja oseba, ki živi v katerem koli drugem bivališču na posesti, ki vsebuje zadevno bivališče, ali pa katera koli oseba, ki živi v bližini zadevnega bivališča ali na posesti, ki vsebuje zadevno bivališče v soseski (Candy Murphy and Associates, 2007: 6).

Podobno je policija v Zahodni Avstraliji ASB opredelila kot kakršno koli »vedenje, ki moti, nadleguje ali ovira druge pri početju stvari, do katerih so upravičeni po zakonu « (McAtamney in Morgan, 2009: 1). Millie idr. (2005: 3) so ASB opredelili kot vedenje, ki »nadleguje, vznemirja ali povzroča nemir pri posameznikih, ki ne pripadajo istemu gospodinjstvu kot kršitelj; tako da je potrebno posredovanje ustreznih oblasti; kazenski pregon in kazen sta lahko neprimerna, saj posamezne sestavine vedenja niso prepovedane $s$ kazenskim pravom, posamično pa pomenijo razmeroma majhna kazniva dejanja «.

Iz zgoraj zapisanega je jasno, da so lahko definicije ASB precej prožne ter da je pri določanju obsega ASB zabrisana meja med kaznivimi in nekaznivimi dejanji (Brown, 2004). V Hongkongu vlada ne uporablja izraza ASB. Namesto tega se za prekrške, ki jih druge države razumejo kot ASB, v Hongkongu običajno uporablja izraz »nevšečnosti v stanovanjski soseski «. Pred letom 2003 za nadzorovanje ASB v mestu ni bilo jasne skupne politike, temveč so v primeru ASB ukrepali precej nesistematično in priložnostno, predvsem z ukrepi, ki so jih omogočali zakoni. Na primer nevšečnosti zaradi hrupa v domovih in namerno odlaganje smeti na javnih mestih so urejali z odlokom o nadzoru hrupa (ang. Noise Control Ordinance) in odlokom o fiksnih kaznih zaradi kršenja javne čistoče (ang. Fixed Penalty (Public Cleanliness Offences) Ordinance). Nekatere druge oblike nespodobnega vedenja, kot so pijanost, grafiti, vandalizem in metanje predmetov z višine, pa so urejali z odlokom o lažjih kaznivih dejanjih (ang. Summary Offences Ordinance).
Ko je leta 2003 izbruhnil SARS, ki je v Hongkongu terjal 299 življenj, je to $\mathrm{v}$ javnosti vzbudilo skrb za javno čistočo na gosto poseljenih mestnih območjih. Da bi izboljšala higieno okolja, je hongkonška vlada maja 2003 sestavila medoddelčno projektno skupino Team Clean. Skupini je predsedoval glavni sekretar za upravo, med najpomembnejšimi oddelki pa so bili urad za stavbe, urad za prehrano in higieno okolja, urad za notranje zadeve in urad za stanovanja. Eno izmed priporočil projektne skupine je bilo, da je treba izboljšati ukrepanje proti najemnikom javnih stanovanj, ki so večkrat kršili zdravstvena načela. V skladu s tem priporočilom je služba za stanovanja v Hongkongu (ang. Hong Kong Housing Authority) avgusta 2003 vpeljala sistem označevanja za izvajanje najemništva $\mathrm{v}$ javnih stanovanjih, da bi se izboljšale higienske in bivalne razmere v javnih stanovanjih na tem območju (Team Clean, 2003). Sistem je temeljil na kazenskih točkah, ki so jih najemniki prejeli, če so storili določen prekršek. Če so zbrali določeno število kazenskih točk, so bili izključeni iz svoje javne stanovanjske enote.

Vendar pa je bil ta sistem označevanja deležen kritik zaradi slabe sprejetosti med ljudmi, nepravičnosti in negativnih socialnih učinkov (Yau, 2011a, 2011b in 2011c). Še pomembneje
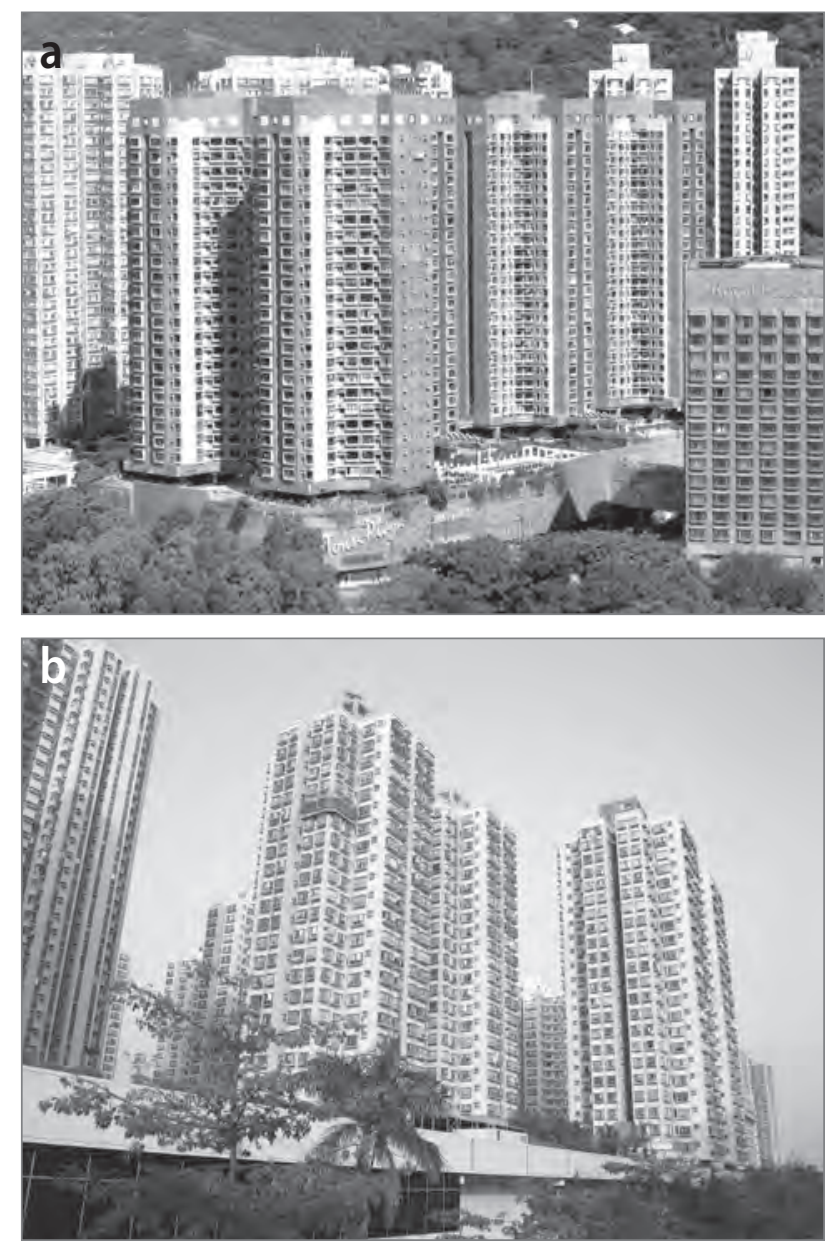

Slika 1: (a) New Town Plaza v Shatinu, (b) Tai Po Centre v Tai Poju (foto: Yung Yau) 
je to, da gre za diskriminatorni sistem, saj so vanj vključeni le stanovalci javnih najemniških stanovanj (vključno z začasnimi stanovanji). Tak selektivni nadzor dejansko ni upravičen, razen če je dokazano, da problemi z ASB v nesocialnih stanovanj- skih sektorjih (na primer subvencionirano lastništvo stanovanj in zasebni stanovanjski sektor) niso veliki. Vlada in novinarji občasno poročajo o primerih ASB v zasebnih stanovanjih (na primer urad za informiranje, 2009; Chiu, 2011), vendar do-

Preglednica 1: Razporeditev anketirancev glede na socialno-demografske lastnosti

\begin{tabular}{|c|c|c|c|c|c|c|}
\hline \multirow[t]{2}{*}{ Lastnost* } & \multicolumn{2}{|c|}{ (0) Najemniki } & \multicolumn{2}{|c|}{ (1) Lastniki - stanovalci } & \multicolumn{2}{|c|}{ Skupno } \\
\hline & $n$ & $\%$ & $n$ & $\%$ & $n$ & $\%$ \\
\hline \multicolumn{7}{|l|}{ Spol (SP) } \\
\hline$(=1)$ moški & 33 & 58,9 & 143 & 61,9 & 176 & 61,3 \\
\hline$(=0)$ ženski & 23 & 41,1 & 88 & 38,1 & 111 & 38,7 \\
\hline \multicolumn{7}{|l|}{ Starost (STAR) } \\
\hline (= 1) 18-24 let & 7 & 12,5 & 11 & 4,8 & 18 & 6,3 \\
\hline$(=2) 25-34$ let & 8 & 14,3 & 33 & 14,3 & 14 & 14,3 \\
\hline$(=3)$ 35-44 let & 11 & 19,6 & 68 & 29,4 & 79 & 27,5 \\
\hline$(=4)$ 45-54 let & 17 & 30,4 & 77 & 33,3 & 94 & 32,8 \\
\hline$(=5)$ 55-64 let & 12 & 21,4 & 30 & 13,0 & 42 & 14,6 \\
\hline (= 6) 65 let ali več & 1 & 1,8 & 12 & 5,2 & 13 & 4,5 \\
\hline \multicolumn{7}{|l|}{ Stopnja izobrazbe $(I Z)$} \\
\hline (= 1) osnovna ali nižja & 10 & 17,9 & 30 & 13,0 & 40 & 13,9 \\
\hline$(=2)$ nižja srednja & 2 & 3,6 & 11 & 4,8 & 13 & 4,5 \\
\hline$(=3)$ višja srednja & 15 & 26,8 & 61 & 26,4 & 76 & 26,5 \\
\hline$(=4)$ matura & 6 & 10,7 & 34 & 25,5 & 40 & 13,9 \\
\hline (= 5) univerzitetna diploma ali več & 23 & 41,1 & 95 & 41,1 & 118 & 41,1 \\
\hline \multicolumn{7}{|l|}{ Povprečni mesečni dohodek v gospodinjstvu $(D O H)$} \\
\hline$(=1)$ manj kot $5.000 \mathrm{HKD}$ & 2 & 3,6 & 7 & 3,0 & 9 & 3,1 \\
\hline (= 2) 5.000-9.999 HKD & 2 & 3,6 & 8 & 3,5 & 10 & 3,5 \\
\hline (= 3) 10.000-14.999 HKD & 3 & 5,4 & 15 & 6,5 & 18 & 6,3 \\
\hline (= 4) 15.000-19.999 HKD & 5 & 8,9 & 18 & 7,8 & 23 & 8,0 \\
\hline (= 5) 20.000-24.999 HKD & 4 & 7,1 & 28 & 12,1 & 32 & 11,1 \\
\hline (= 6) 25.000-29.999 HKD & 15 & 26,8 & 64 & 27,7 & 79 & 27,5 \\
\hline (= 7) 30.000-34.999 HKD & 6 & 10,7 & 39 & 16,9 & 45 & 15,7 \\
\hline (= 8) 35.000-39.999 HKD & 7 & 12,5 & 24 & 10,4 & 31 & 10,8 \\
\hline$(=9) 40.000 \mathrm{HKD}$ ali več & 11 & 19,6 & 24 & 10,4 & 35 & 12,2 \\
\hline (NA) niso želeli odgovoriti & 1 & 1,8 & 4 & 1,7 & 5 & 1,7 \\
\hline \multicolumn{7}{|l|}{ Narodnost (NAR) } \\
\hline (= 1) Kitajci, ki so se rodili ali odraščali v bližini & 51 & 91,8 & 200 & 86,6 & 251 & 87,5 \\
\hline$(=0)$ novi priseljenci iz celinske Kitajske & 3 & 5,4 & 14 & 6,1 & 17 & 5,9 \\
\hline (= 0$)$ druge narodnostne skupine & 1 & 1,8 & 15 & 6,5 & 16 & 5,6 \\
\hline (NA) niso želeli odgovoriti & 1 & 1,8 & 2 & 0,9 & 3 & 1,0 \\
\hline \multicolumn{7}{|l|}{ Število družinskih članov v gospodinjstvu (DRU) } \\
\hline$(=1)$ eden & 4 & 7,1 & 8 & 3,5 & 12 & 4,2 \\
\hline$(=2)$ dva & 5 & 8,9 & 26 & 11,3 & 31 & 10,8 \\
\hline$(=3)$ trije & 14 & 25,0 & 64 & 27,7 & 78 & 27,2 \\
\hline (= 4) štirje & 21 & 37,5 & 97 & 42,0 & 118 & 41,1 \\
\hline$(=5)$ pet & 10 & 17,9 & 26 & 11,3 & 36 & 12,5 \\
\hline$(=6)$ šest ali več & 2 & 3,6 & 10 & 4,3 & 12 & 4,2 \\
\hline skupaj & 56 & 100,0 & 231 & 100,0 & 287 & 100,0 \\
\hline
\end{tabular}

Opomba: $\left(^{*}\right)$ Vrednosti v oklepajih pomenijo vnosne vrednosti za izbrano kategorijo ali slamnate spremenljivke za poznejšo analizo s probitmodelom za urejene podatke. 
slej še ni bila opravljena nobena raziskava o obsegu problemov ASB v hongkonških nesocialnih stanovanjih. Da bi odpravili obstoječo vrzel, se $\mathrm{v}$ tej raziskavi preučuje, kako resen je po mnenju stanovalcev problem ASB v nesocialnih stanovanjih.

\section{Resnost problemov ASB v hongkonških zasebnih stanovanjih}

\subsection{Zgradba ankete in opis anketirancev}

Mnenja stanovalcev zasebnih stanovanj so bila zbrana z anonimnim strukturiranim anketnim vprašalnikom, ki so ga anketiranci izpolnjevali od aprila do junija 2011. Ta pristop je bil uporabljen zato, da bi $\mathrm{k}$ anketi pritegnili čim več ljudi. Za zbiranje podatkov, potrebnih za empirično raziskavo, je bil oblikovan poseben vprašalnik, ki je bil predhodno preizkušen in dopolnjen v skladu s povratnimi informacijami anketarjev. Skupno je bilo intervjuvanih 287 stanovalcev zasebnih stanovanj v okrožjih Tai Po in Shatin. Na slikah 1a in $1 b$ sta prikazani stanovanjski naselji, v katerih so živeli nekateri anketiranci.

V preglednici 1 so predstavljene socialno-demografske lastnosti anketirancev. Anketiranci so med izvajanjem ankete v zasebnih stanovanjih živeli v povprečju 14,8 leta. Večina anketirancev je pripadala višjemu ali srednjemu dohodkovnemu razredu, saj je več kot $75 \%$ anketirancev imelo mesečni dohodek na gospodinjstvo višji od $17.250 \mathrm{HKD}$, kolikor je leta 2006 znašal povprečni mesečni dohodek na gospodinjstvo v Hongkongu (popisni in statistični urad, 2007). Približno polovica anketirancev je bil mlajša od 45 let. Pri tem je imelo 41,1 \% anketirancev visokošolsko izobrazbo (univerzitetno diplomo ali več). $\mathrm{V}$ vzorcu so prevladovala tri- in štiričlanska gospodinjstva (41,8\%). Triintrideset anketirancev (11,5\%) ni bilo kitajskega porekla oziroma so bili novi priseljenci iz celinske Kitajske. V povezavi z lastništvom stanovanj je 231 anketirancev $(80,5 \%)$ živelo v stanovanjih, ki so bila v njihovi lasti. Več kot polovica anketirancev $(58,2 \%)$ je živela v samostojnih hišah, 98 (34,1 \%) jih je živelo v blokih, 22 (7,7 \%) pa v hiši na podeželju.

\subsection{Resnost in vzroki problemov ASB po mnenju anketirancev}

$\mathrm{V}$ osebnih intervjujih smo anketirance vprašali, ali se jim težave z določeno obliko ASB v njihovih stanovanjskih naseljih zdijo resne, pri čemer smo za odgovore uporabili petstopenjsko lestvico ( $5=$ močno se strinjam in $1=$ sploh se ne strinjam). Kot je prikazano v preglednici 2, so anketiranci med vsemi oblikami ASB najpogosteje navajali »hrup «, ki so mu sledili »odpadki ali smeti« in »nepopravljeni odtoki ali pronicanje vode «. Med dvanajstimi preučevanimi oblikami ASB pa anketiranci »kapljanja vode « in »kopičenja odpadkov « niso doživljali kot resna problema, saj sta bila povprečna rezultata zanju nižja od tri.

Poleg tega smo anketirance povprašali o tem, kaj po njihovem mnenju povzroča težave $\mathrm{v}$ njihovih naseljih. Tudi tu smo za odgovore uporabili petstopenjsko Likertovo lestvico $(5=$ močno se strinjam in $1=$ sploh se ne strinjam), v preglednici 3 pa so prikazane ugotovitve. Po mnenju anketirancev je glavni vzrok za težave z ASB v njihovih bivališčih »neučinkovito nadzorovanje ali upravljanje «. Povprečni rezultat za ta vzrok je bil 3,92, kar ga uvršča na najvišje mesto. Neučinkovitemu nadzorovanju ali upravljanju sta sledila »slabo starševstvo « (povprečje $=3,78)$ na drugem mestu in »duševna bolezen ali motnja « (povprečje $=3,63$ ) na tretjem mestu. Medtem ko sta bila »alkohol ali droge $\ll($ povprečje $=2,38)$ in »brezposelnost « (povprečje $=2,75)$ najmanj pomembna vzroka za nastanek problemov ASB.

Iz navedenega je jasno, da se je učinkovito upravljanje stavb intervjuvancem zdelo pomembno pri spopadanju z ASB v zasebnih stanovanjih. Prav tako so kot enega izmed glavnih vzrokov za probleme ASB v zasebnih stanovanjih v Hongkongu

Preglednica 2: Resnost posameznih problemov ASB po mnenju anketirancev $(n=287)$

\begin{tabular}{lll}
\hline Problem & Povprečje & $\sigma$ \\
\hline hrup & 3,72 & 0,96 \\
\hline odpadki ali smeti & 3,68 & 0,87 \\
\hline nepopravljeni odtoki ali pronicanje vode & 3,57 & 0,96 \\
\hline neprimerna uporaba skupnih prostorov ali infrastrukture & 3,53 & 0,93 \\
\hline metanje predmetov z višine & 3,41 & 0,90 \\
\hline vandalizem ali grafiti & 3,28 & 0,87 \\
\hline nezakoniti posli & 3,21 & 0,97 \\
\hline nenadzorovani psi & 3,18 & 0,94 \\
\hline gangsterji & 3,10 & 1,01 \\
\hline vlomi & 3,09 & 0,91 \\
\hline kapljanje vode & 2,99 & 0,96 \\
\hline kopičenje odpadkov & 2,89 & 1,11 \\
\hline
\end{tabular}


Preglednica 3: Vzroki za ASB v stanovanjih po mnenju anketirancev $(n=287)$

\begin{tabular}{lll}
\hline Problem & Povprečje & $\sigma$ \\
\hline neučinkovito nadzorovanje ali upravljanje & 3,92 & 0,86 \\
\hline slabo starševstvo & 3,78 & 0,88 \\
\hline duševna bolezen ali motnja & 3,63 & 0,91 \\
\hline pomanjkanje discipline v šoli & 3,58 & 0,98 \\
\hline dolgčas & 3,31 & 0,77 \\
\hline brezposelnost & 2,75 & 0,82 \\
\hline alkohol ali droge & 2,38 & 0,99 \\
\hline
\end{tabular}

doživljali slabo starševstvo. Te ugotovitve se skladajo z drugimi raziskavami (Millie idr., 2005; Ipsos MORI, 2006), ki so med drugim pokazale, da je slabo starševstvo najpomembneǰ̌i vzrok za nastanek ASB v Združenem kraljestvu. Do podobnega sklepa je prišel tudi avtor tega članka (Yau, 2011b), saj je ugotovil, da slabo starševstvo bistveno vpliva na nastanek problemov ASB v javnih stanovanjih v Hongkongu. Po njegovem mnenju $\mathrm{k}$ temu prispevata dolgi delavnik in pomanjkanje družbene podpore staršem. Glede na te ugotovitve bi morala lokalna vlada nuditi več storitev, da bi podprla zaposlene starše pri dodeljevanju skrbništva nad otroci in vzgoji mladih.

\section{Raven in dejavniki sprejemanja ASB}

Da bi ugotovili, kdo ne prenaša problemov ASB v svojem bivalnem okolju, smo izvedli multivariatno analizo podatkov, zbranih $\mathrm{v}$ anketi. $\mathrm{V}$ strukturiranem anketnem vprašalniku so anketiranci ocenjevali, kako resni in nesprejemljivi se jim zdijo problemi ASB in nevšečnosti v njihovem stanovanjskem naselju. Anketiranci so svoje odgovore označevali na petstopenjski Likertovi lestvici $(5=$ močno se strinjam in $1=$ sploh se ne strinjam). Višji rezultat kaže večje nesprejemanje problemov ASB na kraju prebivanja. Med 287 vprašanimi jih je 99 (34,5\%) odgovorilo, da problemi ASB v njihovih stanovanjskih naseljih niso sprejemljivi, medtem ko jih je 115 (40,1 \%) menilo nasprotno.

Pri tem smo predvidevali, da so ravni nesprejemanja $(N E S)$ anketirancev funkcije več socialno-demografskih dejavnikov, kot so spol (SP), starost (STAR), stopnja izobrazbe (IZ), dohodki gospodinjstva $(D O H)$ in narodnost $(N A R)$, ter stanovanjskih izkušenj in značilnosti, kot so čas bivanja $\mathrm{v}$ javnih stanovanjih $(B I V)$, število družinskih članov v gospodinjstvu $(D R U)$, zadovoljstvo stanovalcev $(Z A D)$ in vrsta stanovanja, v katerem anketiranec živi $(V R S)$. To je matematično prikazano $\mathrm{v}$ enačbi 1:

$$
\begin{aligned}
N E S= & \alpha_{1} S P+\alpha_{2} S T A R+\alpha_{3} I Z+\alpha_{4} D O H+\alpha_{5} B I V \\
& +\alpha_{6} N A R+\alpha_{7} D R U+\alpha_{8} Z A D+\alpha_{9} V R S+\alpha_{10} L A S T+\varepsilon
\end{aligned}
$$

kjer so $\alpha_{i}$ (za $\left.i=1,2, \ldots, 10\right)$ izbrani koeficienti, $\varepsilon$ pa je slučajni člen. $B I V$ je z leti izraženo obdobje, ki ga je anketiranec preživel v trenutnem stanovanju. $Z A D$ pomeni zadovoljstvo anketiranca $s$ splošno kakovostjo naselja in je izmerjeno na petstopenjski lestvici $(5=$ zelo zadovoljen in $1=$ zelo nezadovoljen). VRS je slamnata spremenljivka, ki ustreza vrednosti 1 , če anketiranec živi v visoki večstanovanjski stavbi, in 0 , če ne. $L A S T$ je slamnata spremenljivka, ki ustreza vrednosti 1 , če je anketiranec lastnik stanovanja, v katerem živi, in 0 , če ni. Pomeni in merilne lestvice drugih slamnatih spremenljivk so podrobneje predstavljeni v preglednici 1 . $\mathrm{V}$ preglednici 4 so prikazane povprečne vrednosti vseh spremenljivk v enačbi 1 . Ker je odvisna spremenljivka INT ordinalna, lahko s pomočjo probitmodela za urejene podatke dobimo robustnejšo oceno modela, kot pa bi jo z običajno metodo navadnih najmanjših kvadratov. Po izključitvi manjkajočih podatkov je bilo v analize vključeno 280 opazovanj. Rezultati izračuna enačbe 1 so predstavljeni v preglednici 5.

Izračunana koeficienta spremenljivk $S P$ in $I Z$ sta statistično pomembna na ravni $1 \%$, za spremenljivki $B I V$ in $V R S$ pa sta koeficienta pomembna na ravni $5 \%$. Koeficient spremenljivke $D R U$ je mejno pomemben na ravni $10 \%$. Medtem ko starost $(S T A R)$, dohodek gospodinjstva $(D O H)$, narodnost $(N A R)$, zadovoljstvo stanovalcev $(Z A D)$ in lastništvo stanovanj $(L A S T)$ ne vplivajo močno na raven nesprejemanja, niti na ravni $10 \%$. Kot kažejo rezultati izračuna, so anketiranci moškega spola slabše sprejemali prevladujoče probleme ASB v svojih stanovanjskih naseljih, ceteris paribus. Poleg tega zadovoljstvo stanovalcev ni imelo bistvenega vpliva na raven nesprejemanja. Presenetljivo je, da te ugotovitve nasprotujejo drugi raziskavi o javnih stanovanjih (Yau, 2011b), v skladu $s$ katero so moški lažje prenašali probleme ASB, raven nesprejemanja pa se je večala $\mathrm{z}$ nezadovoljstvom stanovalcev.

Kot nakazujeta pozitivni oziroma negativni predznak koeficientov spremenljivk $I Z$ in $B I V$, so anketiranci, ki so bili bolj izobraženi in so $\mathrm{v}$ trenutnem stanovanju živeli manj časa, pogosteje menili, da problemi ASB v njihovem bivalnem okolju niso sprejemljivi. Anketiranci, ki so živeli v visokih večstanovanjskih stavbah v Hongkongu, so slabše sprejemali probleme ABS kot anketiranci, ki so živeli v hišah na podeželju. To je 
Preglednica 4: Povprečne vrednosti odgovorov po posameznih spremenljivkah, uporabljenih pri analizi s probitmodelom za urejene podatke

\begin{tabular}{|c|c|c|c|}
\hline Spremenljivka & Razpon & Povprečje & $\sigma$ \\
\hline NES & 5 = močno se strinjam $/ \ldots / 1$ = sploh se ne strinjam & 2,92 & 0,27 \\
\hline$S P$ & 1 = moški; 0 = ženski & 0,61 & 0,49 \\
\hline STAR & $6=65$ let ali več $/ \ldots / 1=18-24$ let & 3,49 & 1,22 \\
\hline IZ & 5 = univ. dipl. ali več $/ . . . / 1=$ osnovna ali nižja & 3,64 & 1,41 \\
\hline $\mathrm{DOH}$ & $9=40.000 \mathrm{HKD}$ ali več $/ . . . / 1$ = manj kot $5.000 \mathrm{HKD}$ & 5,98 & 2,03 \\
\hline BIV & 28 let $/ . . . / 1$ leto & 14,82 & 7,90 \\
\hline NAR & 1 = Kitajec, ki se je rodil ali odraščal v okolici; 0 = drugi & 0,88 & 0,32 \\
\hline$D R U$ & $6=$ šest ali več $/ \ldots / 1$ = ena & 3,60 & 1,10 \\
\hline$Z A D$ & 5 = zelo zadovoljen $/ . . . / 1$ = zelo nezadovoljen & 3,08 & 0,87 \\
\hline VRS & 1 = stanovanje v visoki stavbi; 0 = hiša na podeželju & 0,92 & 0,27 \\
\hline LAST & 1 = lastnik - stanovalec; 0 = najemnik & 0,80 & 0,40 \\
\hline
\end{tabular}

Preglednica 5: Rezultati probitanalize o ravni nesprejemanja

\begin{tabular}{lllll}
\hline Spremenljivka & Koeficient & Standardna napaka & z-statistika & $p$-vrednost \\
\hline$S P$ & 0,5536 & 0,1322 & 4,1867 & 0,0000 \\
\hline STAR & $-0,0614$ & 0,0645 & $-0,9523$ & 0,3409 \\
\hline$I Z$ & 0,3552 & 0,0494 & 7,1892 & 0,0000 \\
\hline$D O H$ & 0,0195 & 0,0362 & 0,5404 & 0,5889 \\
\hline$B I V$ & $-0,0228$ & 0,0114 & $-2,0021$ & 0,0453 \\
\hline$N A R$ & $-0,2072$ & 0,2463 & $-0,8411$ & 0,4003 \\
\hline DRU & $-0,1159$ & 0,0673 & $-1,7223$ & 0,0850 \\
\hline ZAD & 0,0692 & 0,0756 & 0,9163 & 0,3595 \\
\hline VRS & 0,4445 & 0,2238 & 1,9861 & 0,0470 \\
\hline LAST & 0,0051 & 0,2172 & 0,0235 & 0,9812 \\
\hline odvisna spremenljivka: & $I N T$ & stevilo opazovanj: & 280 \\
\hline prilagojen R-kvadrat: & 0,1001 & Schwarzov kriterij: & 3,1456 \\
\hline Akaikov informacijski kriterij: & 2,9638 & Hannan-Quinnov kriterij: & 3,0367 \\
\hline LR-statistika: & 89,2218 & p (LR-statistika): & 0,0000
\end{tabular}

popolnoma razumljivo, saj je bivalno okolje v zasebnih stolpnicah v Hongkongu gosteje poseljeno in zato lahko neprimerno obnašanje posameznega stanovalca bistveno bolj neposredno vpliva na veliko število drugih stanovalcev. $\mathrm{Na}$ primer zaradi kopičenja smeti v stanovanju morajo ljudje, ki živijo v bližini, prenašati smrad in nehigienske pogoje. Prav tako so se prebivalci Hongkonga po boleči izkušnji z izbruhom SARS leta 2003 začeli bolj zavedati groznih posledic nekakovostnega življenjskega okolja, zlasti v visokih večstanovanjskih stavbah. Zato torej prebivalci visokih večstanovanjskih stavb v mestu slabše sprejemajo ASB.

\section{Težave pri obvladovanju ASB v zasebnih stanovanjih}

Kot je bilo omenjeno zgoraj, je večina anketirancev širjenje ASB pripisala neučinkovitemu nadzorovanju ali obvladovanju, $\mathrm{s}$ čimer so posredno izrazili mnenje, da se lahko z ustreznim upravljanjem večstanovanjskih stavb zmanjša probleme ASB. Vendar obvladovanje ASB v nesocialnih stanovanjih ni tako preprosto kot v socialnih. V socialnih ali javnih stanovanjih imajo najemodajalci običajno stroge najemniške pogoje, s katerimi vplivajo na vedenje najemnikov. Na podlagi pogojev prejemanja socialne pomoči lahko najemnika izselijo iz socialnega stanovanja zaradi ponavljajočih se primerov ASB ali nesprejemljivega vedenja (Yau, 2011a). Nekateri socialni najemodajalci pa najemnike spodbujajo $\mathrm{k}$ odgovornemu vedenju tako, da jim, če zanje v določenem časovnem obdobju niso prejeli nobenih pritožb, dajejo prednost pri vzdrževalnih delih, podarjajo komplete vrtnarskih pripomočkov ali darilne bone (Lupton idr., 2003; Jacobs idr., 2005; Jacobs, 2008). V zasebnem najemniškem sektorju se ASB nadzoruje predvsem s pogoji najemnih pogodb (Wright, 2011). Čeprav imajo zasebni najemodajalci na voljo stroge ukrepe, kot je prekinitev pogodbe, pa se takih možnosti le redko poslužujejo, ker bi lahko s prekinitvijo najemnega razmerja imeli nižje dohodke, saj morda za določeno obdobje ne bi prejeli najemnine. Lastniki se za prekinitev najemnega razmerja odločijo, če nevšečnosti ali ASB slabo vplivajo na najem, tako da njihova posestva spravljajo na slab glas. 
Stvari še dodatno otežuje dejstvo, da so mnogi stanovalci v zasebnem sektorju v Hongkongu obenem tudi lastniki stanovanj, $\mathrm{v}$ katerih živijo. Pri tej skupini stanovalcev bi s prisilno izselitvijo kršili njihovo pravico do zasebne lastnine. Pravzaprav imamo v nesocialnih stanovanjih na voljo le dve možnosti za ukrepanje: primere lahko prijavimo oblastem (na primer policiji, uradu za varstvo okolja ali uradu za prehrano in higieno okolja) ali pa na sodišču zaprosimo za sodno prepoved. Seveda se lahko upravnikom večstanovanjskih stavb pisno pritožimo, vendar imajo omejena pooblastila za obravnavanje problemov ASB. Poleg tega upravniki večstanovanjskih stavb zaradi dvostranskega razmerja med njimi in lastniki stanovalci neradi posegajo v sosedske spore, ki nastanejo zaradi ASB. Po eni strani bi moral upravnik ščititi pravice in interese solastnikov v zasebnem stanovanjskem naselju, saj je pooblaščen, da zagotavlja upoštevanje pravnega dokumenta, ki določa pravice, interese in dolžnosti solastnikov, stanovalcev in upravnikov stanovanj $\mathrm{v}$ večlastniškem naselju v zvezi z nadzorom, vzdrževanjem in upravljanjem naselja (ang. deed of mutual covenant, $\mathrm{v}$ nadaljevanju: DMC; urad za notranje zadeve, 2001). Po drugi strani pa upravnika načeloma skupaj izberejo vsi solastniki v naselju. Upravnik torej nadzoruje vedenje vseh solastnikov, obenem pa je njihov zastopnik. Pri reševanju sosedskih sporov je pogosto ena stran $s$ posredovanjem zadovoljna, druga pa ne.

Čeprav so upravniki stanovanj izvajalci DMC, pa niso pooblaščeni za kaznovanje kršiteljev. V primeru ASB se morajo glede možnosti ukrepanja zanašati na pravni sistem (na primer sodne prepovedi zoper kršitelje ali odškodninski zahtevki), vendar pa so sodni postopki zelo pogosto dolgotrajni in dragi. Upravniki stanovanj so torej v težkem položaju, zaradi česar pri ASB in sporih med sosedi neradi posredujejo. Takim zadevam se običajno izogibajo, razen če vplivajo na veliko število stanovalcev. To jasno prikazujejo tudi rezultati ankete. Med anketiranci, ki so se zaradi ASB pisno pritožili pri upravnikih stanovanj, jih je le $22 \%$ menilo, da jim bodo upravniki lahko pomagali odpraviti ASB ali nevšečnosti, ki so vplivale predvsem nanje. Po drugi strani je v tej skupini $67 \%$ anketirancev menilo, da bi lahko upravniki stanovanj po prejemu pritožb določeno obliko ASB učinkovito odpravili ali ublažili, če bi vplivala na veliko stanovalcev v njihovem naselju.

\section{Sklep in predlogi za nadaljnje raziskave}

Nevšečnosti v stanovanjskih soseskah in problemi ASB v stanovanjskem sektorju lokalnim prebivalcem in vladam po svetu že dolgo povzročajo številne težave, pri čemer je glavna pozornost namenjena socialnim ali javnim stanovanjem. Ta enostranska usmerjenost je morda posledica marginalizacije socialnih stanovanj (Forrest in Murie, 1988; Malpass, 1990), ni pa pojasnjeno, ali ta težava pri drugih vrstah stanovanj ne obstaja ali pa je preprosto prezrta. Pravzaprav je hongkonška laburistična stranka (1995: 7) potrdila, da je »pri zasebnih najemnikih in lastnikih stanovalcih veliko primerov protisocialnega vedenja «. Zato članek prispeva nova spoznanja na tem področju znanja tako, da preučuje mnenja 287 stanovalcev zasebnih stanovanj v Hongkongu glede problemov v soseski, $\mathrm{v}$ kateri živijo. Kot kažejo ugotovitve ankete te raziskave, se stanovalci zasebnih stanovanjskih naselij pritožujejo zaradi resnih problemov v soseski, kot sta hrup in odlaganje smeti. Poleg tega se je z multivariatno analizo razkrilo, da anketiranci $\mathrm{z}$ višjo stopnjo izobrazbe in krajšim časom bivanja $\mathrm{v}$ visoki večstanovanjski stavbi slabše sprejemajo probleme ASB v svojem bivalnem okolju. Čeprav je spopadanje z ASB v zasebnih stanovanjih odvisno od pripravljenosti sosedov in skupnosti, da to vedenje prijavijo ustrezni ustanovi (Wright, 2011), je večina anketirancev menila, da upravniki njihovih stanovanj pritožb niso sposobni ustrezno obravnavati.

Čeprav je ta raziskava omejena, saj je bila na primer izvedena na majhnem vzorcu anketirancev, pa lahko vendarle spodbudi več novih raziskav o ASB ali drugih nevšečnostih pri različnih vrstah stanovanj. Morda se bodo strokovnjaki pri določanju smeri nadaljnjih raziskav osredotočili na to, zakaj se določene vrste ASB (na primer hrup) tako pogosto pojarljajo in kateri ukrepi so učinkoviti za reševanje problema. Pravzaprav bi lahko ta vprašanja raziskovali z vidika transakcijskih stroškov. Ta raziskava in mnoge druge (na primer Lovbakke, 2007; Innes, 2011; Yau, 2011b) so pokazale, da smetenje ali nepravilno odlaganje odpadkov spada med najhujšse prekrške. Najbrž je tako zato, ker so stroški ukrepanja (vključno s postavljanjem pravil, z ugotavljanjem kršitev in zbiranjem dokazov) zelo visoki. Lahko si predstavljamo, kako težko je dokazati, ali je kup smeti na hodniku tja postavil nekdo iz določenega gospodinjstva, razen če imamo za to dejanske priče. Podobno tudi nadzorni ukrepi, ki zahtevajo zelo visoke transakcijske stroške (na primer uporaba zakonsko predpisanih odlokov o ASB), niso uspešni pri reševanju nevšečnosti.

\section{Yung Yau}

City University of Hong Kong, Department of Public and Social Administration, Kowloon Tong, Hongkong

E-pošta: y.yau@cityu.edu.hk

\section{Zahvala}

Zgodnejša različica tega članka je bila decembra 2011 predstavljena na konferenci skupnosti za stanovanjske raziskave v Aziji in Tihooceanskem območju 2011 (ang. 2011 Asia-Pacific Network for Housing Research Conference) v Hongkongu. Avtor se zahvaljuje moderatorju in udeležencem konference za njihove komentarje, neizmerno pa je hvaležen tudi študentom mestne univerze v Hongkongu za njihovo pomoč pri anketnem vprašalniku. 


\section{Viri in literatura}

Agyemang, C., Van Hooijdonk, C., Wendel-Vos, W., Lindeman, E., Stronks, K., in Droomers, M. (2007): The association of neighbourhood psychosocial stressors and self-rated health in Amsterdam, the Netherlands. Journal of Epidemiology and Community Health, 61(12), str. 1042-1049. DOI: 10.1136/jech.2006.052548

Ameriški popisni urad (2010): American housing survey for the United States: 2009 - current housing report. Washington, DC, United States Department of Housing and Urban Development and United States Census Bureau.

Avstralski statistični urad (2006): Crime and safety, Australia: April 2005. Sydney.

Brown, A. (2004): Anti-social behaviour, crime control and social control. The Howard Journal of Criminal Justice, 43(2), str. 203-211. DOI: $10.1111 /$ j.1468-2311.2004.00321.x

Candy Murphy and Associates (2007): Third party complaints of anti-social behaviour in the private residential tenancy sector. Dublin, Private Residential Tenancies Board.

Carr, H., in Cowan, D. (2006): Labelling: Constructing definitions of anti-social behaviour? V: Flint, J. (ed.): Housing, urban governance and anti-social behaviour: Perspective, policy and practice, str. 57-78. Bristol, Policy Press.

Chiu, A. (2011): Injunction granted to curb incense-burning. South China Morning Post, 4. 6. 2011, str. City1.

Curtis, L. J., Dooley, M. D., in Phipps, S. A. (2004): Child well-being and neighbourhood quality: Evidence from the Canadian national longitudinal survey of children and youth. Social Science and Medicine, 58(10), str. 1917-1927. DOI: 10.1016/j.socscimed.2003.08.007

Enota lokalne vlade za informiranje (1997): Community safety: Consultation in advance of the Crime and Disorder Bill. London, Home Office.

Flint, J., in Nixon, J. (2006): Governing neighbours: Anti-social behaviour orders and new forms of regulating conduct in the UK. Urban Studies, 43(5-6), str. 939-955. DOI: 10.1080/00420980600676386

Forrest, R., in Murie, A. (1988): Selling the welfare state: The privatisation of public housing. London, Routledge.

Innes, J. (2011): Public perception. V: Chaplin, R., Flatley, J., in Smith, K. (ur.): Crime in England and Wales 2010/01, str. 82-99. London, Home Office.

Inšpektorat za kazensko pravosodje na Severnem Irskem (2008): Anti-Social Behaviour Orders - an inspection of the operation and effectiveness of $A S B O$ s. Belfast.

Ipsos MORI (2006): Public attitudes to parenting. London.

Jacobs, K. (2008): Contractual welfare ideology and housing management practice: The deployment of 'tenant incentive schemes' in Australia. Urban Policy and Research, 26(4), str. 467-479. DOI: 10.1080/08111140801898563

Jacobs, K., Seelig, T., Easthope, H., in Slatter, M. (2005): A review of housing management tenant incentive schemes, AHURI positioning paper no. 86. Melbourne, Australia Housing and Urban Research Institute.

Jacobson, J., Millie, A., in Hough, M. (2008): Why tackle anti-social behaviour. V: Squires, P. (ur.): ASBO nation: The criminalisation of nuisance, str. 37-55. Bristol, The Policy Press.

Kraljevi inštitut za stanovanjski sektor (1995): Neighbour nuisance: Ending the nightmare. Coventry.

Laburistična stranka (1995): A quiet life: Tough action on criminal neighbours. London.
Lovbakke, J. (2007): Public perception. V: Nicholas, C., Kershaw, C. in Walker, A. (ur.): Crime in England and Wales 2006/07, str. 95-111. London, Home Office.

Lupton, M., Hale, J., in Sprigings, N. (2003): Incentives and beyond? The transferability of the Irwell Valley Gold Service to other social landlords. London, Office of the Deputy Prime Minister.

Malpass, P. (1990): Reshaping housing policy: Subsidies, rents, and residualisation. London, Routledge.

McAtamney, A., in Morgan, A. (2009): Key issues in antisocial behaviour (= Research in practice summary paper no. 5). Griffith, Australia Institute of Criminology.

Millie, A., Jacobson, J., Mcdonald, E., in Hough, M. (2005): Anti-social behaviour strategies: Finding a balance. York, Joseph Rowntree Foundation.

Millie, A. (2009): Anti-social behaviour. Berkshire, Open University Press.

Pacione, M. (1982): Evaluating the quality of the residential environment in a deprived council estate. Geoforum, 13(1), str. 45-55. DOI: 10.1016/0016-7185(82)90007-0

Scott, S., in Parkey, H. (1998): Myths and reality: Anti-social behaviour in Scotland. Housing Studies, 13(3), str. 325-345. DOI: 10.1080/02673039883317

Popisni in statistični urad (2007): 2006 population by-census - thematic report: Household income distribution in Hong Kong. Hongkong.

Team Clean (2003): Report on measures to improve environmental hygiene in Hong Kong. Hongkong.

Urad škotske vlade za socialne raziskave (2007): Use of anti-social behaviour orders in Scotland. Edinburgh.

Urad za informiranje (2009): LCQ6: Government attaches great importance to incidents of objects being thrown from height. Hongkong.

Urad za notranje zadeve (2001): Building management. Hongkong.

Wright, G. (2011): Review of housing related anti-social behaviour policies and interventions in the UK, research paper BRT 1/2011. Belfast, Department for Social Development.

Yau, Y. (2010): Občutek pripadnosti skupnosti in sodelovanje lastnikov pri upravljanju večstanovanjskih stavb: raziskava v Hongkongu [Sense of community and homeowners' participation in housing management: a study in Hong Kong]. Urbani izziv, 21(1), str. 51-60 [126-135]. DOI: 10.5379/urbani-izziv-2010-21-01-005

Yau, Y. (2011a): On the anti-social behaviour control in Hong Kong's public housing. Housing Studies, 26(5), str. 701-722. DOI: 10.1080/ 02673037.2011.581911

Yau, Y. (2011b): Ruling out trouble: Unacceptable behaviour and its control in Hong Kong's public housing. Habitat International, 36(1), str. 11-19. DOI: 10.1016/j.habitatint.2011.05.001

Yau, Y. (2011c): Social impacts of the marking scheme in public housing in Hong Kong. Social Indicators Research, 107(2), str. 281-303. DOI: 10.1007/s11205-011-9837-2 